\title{
Building of a space form of the flexible inextensible one-layer conic shell
}

\section{Construcción de matriz espacial de cascarilla cónica plegable de una capa}

\author{
Marina V. Byrdina*, Mikhail F. Mitsik, Lema A. Bekmurzaev, \\ Svetlana V. Kurenova, Anastasiya A. Movchun \\ Institute of Service Sector and Business (branch) of Don State Technical University in \\ the city of Shakhty \\ *byrdinamarina@mail.ru
}

(recibido/received: 01-December-2020; aceptado/accepted: 27-February-2021)

\begin{abstract}
The paper covers the visualization of a volume-space form of the flexible inextensible one-layer shell that is represented in the stress and strain state appearing during fastening the shell on the upper edge and its free location below the fastening border in the field of gravitational and elastic forces of the material. With no account taken of the gravitational forces, the shell is a right circular flattened cone. A developed program module can be used in designing and calculating the thin-wall shell structures during their non-linear deformation and their visualization. Visualization of the space form of the shell structure can be used for simulating various products, for instance, the cone antennae or the textile products, flexible elastic shells in the hydraulic engineering, etc.
\end{abstract}

Key words: Maple package; One-layer structure; Shell forming; Thin elastic shell; Variational problem.

\section{RESUMEN}

Aquí se considera la visualización de una matriz volumétrica espacial de la cascarilla cónica plegable de una sola capa. Se representa la cascarilla en el estado de estrés y tensión registrado, cuando se fija la cascarilla en el borde superior y en su localización bajo del borde de anclaje en la campo de fuerzas elásticas y de gravedad del material. Sin tener en cuenta las fuerzas de gravedad, se define la cascarilla como un cono recto circular truncado. Se puede usar el módulo de programa desarrollado para diseñar y calcular estructuras de cascos con paredes delgadas expuestas a deformación no lineal así como durante su visualización. Se puede usar la visualización de la matriz espacial de la estructura de casco para simular diversos productos, por ejemplo, antenas cónicas o productos textiles, cascarillas plegables para ingeniería hidráulica, etc.

Palabras claves: Paquete maple; Estructura de una capa; Formación de cascarillas; Cascarilla plegable delgada; Problema de variación.

\section{INTRODUCTION}

In the modern economic environment, the light industry enterprises and trading organizations are severely competing with the Russian and foreign companies. In this context, the issues of supplying 
the population with the high-quality clothes are getting particularly important provided that the manufactured products cost price is decreased.

Improvement of the clothes designing process is aimed at its automation and at introducing the automated design systems into the clothes manufacturing process. The design automation will cut down the production costs drastically, reduce the designing time, allow the enterprises to change the models quickly and flexibly and, as a consequence, increase demand for the garments and their competitiveness.

The most important factors, which ensure demand for the clothes and their sale, are their appearance, price and wear resistance. Quality of the future products and their design are built at a stage of the clothes designing. An important problem of the clothes designing is the building of their volume-space form, when a product is simulated as a flexible inextensible shell whose form is influenced by the fabric gravitational forces and the bending elastic forces.

The paper is aimed at developing a method and a programs system of visualizing the volume and space form of the thin-walled flexible conic shell in the strain and stress state that appears in the field of gravitational and elastic forces during fastening the shell on the upper edge. The shell form is visualized in an environment of a package of the applied mathematical programs Maple 2015.

The research tasks are as follows:

1) to set a problem of determining a space form of the thin-walled elastic conic shell with a fastened upper edge;

2) to show a solution to the boundary problem for a case of shells of big conicity for a shell surface element in a parametrical form;

3) to develop the programs package in the Maple environment on visualizing a space form of the elastic shell of big conicity and for large deformations.

The studied problem for determining a space form of the products, which are simulated as a flexible, extensible, flexible shell, is important because the issue is of interest to many leading world companies in the field of the fashion industry, in the sphere of advertising products of the textile goods, to design the conical spiral antennae, to design the products in the form of thin elastic shells in the medical engineering, to design the protective hydraulic structures in the hydraulics, etc.

At present, almost all the leading world companies in the field of developing the program products for the fashion industry are equipping their automated design systems with a clothes forming module: in the case of Gerber company (England) this is the package APDS-3D, in the case of PAD System (Canada), this is the module 3D Sample. Investronika (Spain) and Lectra (France) also say about their developments (Frolovsky \& Landovsky, 2004).

The expansive and pragmatic modern advertisement and the graphic design, which comply with the market laws, deal with the fundamentals of the textile designer profession, put forward the tasks of training the specialists for companies of a new type. Modern methods of the advertisement and the graphic design are different from those of traditional fashion designers, when excluding them in a large field in terms of methods of setting the advertising graphics problems, in terms of the aesthetics, the ways of consuming the advertising products and the ways of their decorative design. In view of this, what is important is a problem of developing a theory of new applications on the decorative design of textile products, which are also new applications in a theory of the advertising graphical design.

Various products and devices on the basis of conical surfaces with the plane and space evolvent curves are widely adopted in the science and technology. The papers analysis in this direction showed that such approaches are used in simulating the comical antennae with two spiral layers of co-polarization to transmit the high-frequency signals (Buzov, 2010; Kolin, 2009). 


\section{MATERIALS AND METHODS}

\subsection{A notion of thin elastic inextensible shell}

The models, which are considered in this paper, can be described by a notion of the thin shell. For instance, for fabrics, the material thickness is about $h_{T}=1 \mathrm{MM}$, while the length of circumference of the cone top (waist) averages $70 \mathrm{~cm}$, the ratio

$$
\delta=\frac{h_{T}}{2 \pi R_{t}}=\frac{10^{-3}}{0,7}=\frac{1}{700}<\frac{1}{20}
$$

in other words, a condition of the product simulation in the form of a thin shell is fulfilled. The value $\delta$ is a relative calculation error with no account taken of the product thickness, its value is no more than $0.5 \%$.

A middle surface of the thin shell is a surface that is equidistant from its external surfaces. Then the thin shell form means a form of its middle surface with description of the theoretical research to an accuracy of $\delta$ from (1).

The problems, which are solved by the shells theory, are widely used in the engineering, and the theoretical fundamentals for their calculation are well developed now. The offered theories can be used for the shells made of perfect materials: elastic, elastic-plastic, viscoelastic, flexible inextensible materials. The technical theory of thin shells calculation (Kolin, 2009) is taken as a basis of calculating the majority of the shell covers that are used in the construction practice. According to this theory, the shell material is considered as elastic, the direct normal hypothesis is regarded as true: a rectilinear element, which is perpendicular to the middle surface to the deformation, remains strain and perpendicular to the deformed middle surface and does not change its length. Apart from that, the conditions of normality of stresses on the areas that are parallel to the middle surface, are fulfilled. Apart from that, they are considered as small to negligence in comparison with other stresses. However, the shell calculation, which are offered in the engineering, do not take into account considerable bending shell deformations that are considered in the problems in question and, respectively, cannot be used for calculating the space form of a flexible inextensible conic shell with a fastened upper edge and that is located freely in the field of gravitational and elastic forces.

At present, solving even such a simplified problem under set boundary conditions on the loop presents significant mathematical difficulties. In order to obtain the dependencies, which are simpler and more convenient for practical calculations, an influence of various impacts upon the stress and strain state, which appears in the shell, is analyzed. The authors consider the shell torques as small and neglect them. In this case, the stress state is determined by normal, shearing forces and the material elastic forces. Such a "no-torque" state takes place in fulfilling the following conditions:

1) the shell is thin, has a surface changing without the material fractures and the thickness abrupt change;

2) elastic properties of the shall material must change gradually too;

3) distributed load upon the shell changes gradually and is continuous;

4) the conditions of fastening the shell boundary are ensuring the freedom of the normal direction movement to the surface below a level of the material fastening.

This paper considers the flexible inextensible conic shells that are surfaces of the zero Gaussian curvature, which ensures the fulfillment of the abovementioned conditions.

\subsection{Review of methods on the flexible inextensible elastic shell forming and their assessment}


The papers of famous scientific schools on determining a form of the cylindrical surfaces made by S.N. Bulatov and V.A. Kozlov (2003) and others solve the problems of forming of the elastic shells that are loaded by the external effects (Buzov, 2010), or they solve the problems of the shell structures stability (Kolin. 2009; Kozlov, 2003). Apart from that, the variational methods are used too, or the shell form is determined through solving a system of nine differential equations of the mechanics of deformable solids. The computer methods of designing the clothes are developed in the school of V.D. Frolovsky and V.V. Landovsky (2004). The variational methods on the basis of the finite-difference schemes (Alfutov, 2010; Ohmori \& Yamamoto, 1998) are also used for simulating the composite surfaces. It should be noted that the famous authors in their papers consider only the numerical methods of solving the problems of the flexible inextensible elastic shells forming. This paper offers a numerical and analytical method of determining the shell space form. The problem on determining the shell space form is solved on the basis of classical methods of mathematics, theoretical mechanics and continuum mechanics.

A form of flexible inextensible conic shell is determined on the basis of a principle of minimum potential energy that is comprised in the shell in the field of bending gravitational and elastic forces. When following the principle of minimum potential energy, a problem of the flexible inextensible flexible shell forming boils down to a variational problem for minimizing the functional.

$$
K \int_{t_{1}}^{t_{2}} \rho(x, y, z) \cdot\left(L-\sqrt{L^{2}-\left(r(t)-R_{T}\right)^{2}}\right) d t+M \int_{t_{1}}^{t_{2}} B(x, y, z)\left(R_{T}-r(t)\right)^{2} d t \rightarrow \min
$$

The curve $r(t)$ is sought-for, with which the functional reaches the least value. The problem for minimizing the functional (2) is solved provided that the shell length is constant in any horizontal section, which is equal to $2 \pi R$, this sets an integral constraint

$$
\int_{0}^{2 \pi} \sqrt{r^{2}(t)+\left(\frac{d r}{d t}\right)^{2}} d t=2 \pi R
$$

Solving the problem for minimizing the functional (2) boils down to the differential equation solution

$$
\rho \cdot g \cdot\left(L-\sqrt{L^{2}-\left(r(t)-R_{t}\right)^{2}}\right)+\frac{B}{2 I} \cdot\left(R_{t}-r(t)\right)^{2}-\lambda \frac{r^{2}(t)}{\sqrt{r^{2}(t)+\left(\frac{d r}{d t}\right)^{2}}}=C_{1}
$$

which, in its turn, is solved by the numerical methods. All the methods used have a high degree of reliability. Theoretical methods of the shell form calculation were assessed by the experimental research.

The experiments solved a problem of finding a space form of the flexible inextensible conic shell that is fastened on the upper edge and located freely in the field of gravitational and elastic forces. The textile fabric was regarded as an example of this shell. The experiments are aimed at checking the obtained theoretical model describing the shell space form, and at assessing the disagreements between a theoretical curve and an experimental one.

In order to perform the set problem, an experiment was carried out, which consisted of 40 tests, which were in vertexes of the matrix of planning the full factorial experiment according to the Box-Wilson 
plan in the case of selecting three optimization parameters. The quantity and composition of the tests were determined on the condition of adequacy of the product main parameters in the experiment and the theoretical research, and representativity the selection totality. In order to solve a problem for finding the products space form, the twin-woven fabrics of dress range were used.

\section{RESULTS AND DISCUSSION}

\subsection{Boundary problem for describing the shell form}

The authors consider a problem of determining a form of the bending elastic shell with the fastened upper edge along circumference of the radius $R_{t}$ and the shell that is located freely in the field of the gravitational and elastic forces.

In order to simplify the problem, the authors suppose that without the gravitational forces influence, the product is a lateral surface of the forward circular truncated loop. For instance, such a structure is possible for a conic skirt (Figure 1).

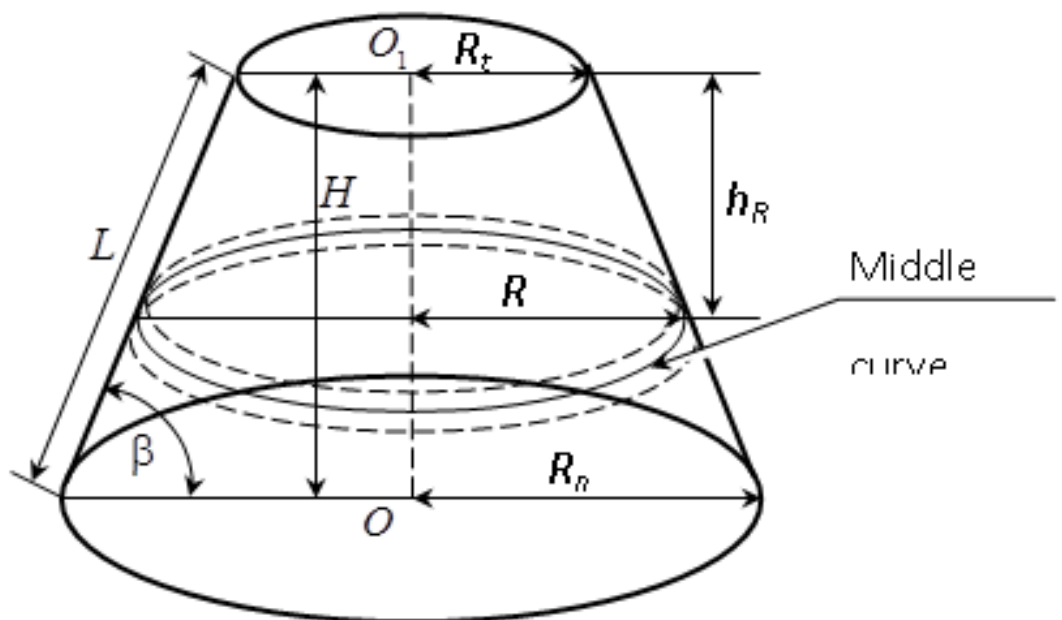

Figure 1. Right circular truncated cone with elements of partition, which is parallel to a horizontal plane

Here: $L-$ is a length of the generatrix of the cone lateral surface;

$\beta-$ is an angle between the cone generatrixt and the base plane;

$R_{t}, R_{n}-$ are radiuses of the cone top and bottom;

$H-$ is a height of the cone.

As the papers (Frolovsky \& Landovsky, 2005; Lan \& Liu, 2011) show, a form of the flexible inextensible conic shell is determined on the basis of a principle of minimum potential energy, which is comprised in a surface element of the shell located in the field of the bending gravitational and elastic forces. Application of the principle of minimum potential energy leads to a variational problem for finding the functional.

$$
\frac{g \cdot L}{\cos \beta} \int_{0}^{2 \pi} \rho(\varphi) \cdot\left(L-\sqrt{L^{2}-\left(r(\varphi)-R_{t}\right)^{2}}\right) d \varphi+\frac{L}{2 I \cos \beta} \int_{0}^{2 \pi} B(\varphi)\left(R_{t}-r(\varphi)\right)^{2} d \varphi \rightarrow \min
$$

where: $\rho(\varphi)$ - is a surface density of the shell;

$g-$ is a gravitational force acceleration;

$I-$ is the central moment of inertia for the shell material; 


$$
\begin{aligned}
& B(\varphi)-\text { a bending stiffness for the shell material; } \\
& \rho(\varphi)-\text { is a polar radius. }
\end{aligned}
$$

The variational problem of the functional minimization (4) must be solved provided that the shell length is constant in any horizontal section, which is equal to $2 \pi R$, which sets an integral constraint

$$
\int_{0}^{2 \pi} \sqrt{r^{2}(\varphi)+\left(\frac{d r}{d \varphi}\right)^{2}} d \varphi=2 \pi R
$$

However, in the form $(4,5)$ solving the problem for determining the space form of the flexible inextensible shell is possible only for relatively small deformations of the shell, or for the small conicity shells. For the big conicity shells, a form of the border of shell projection to the horizontal plane is a curve that is not described unambiguously in the polar coordinate system, since several values of the polar radius can correspond to a value of the polar angle (Figure 2).

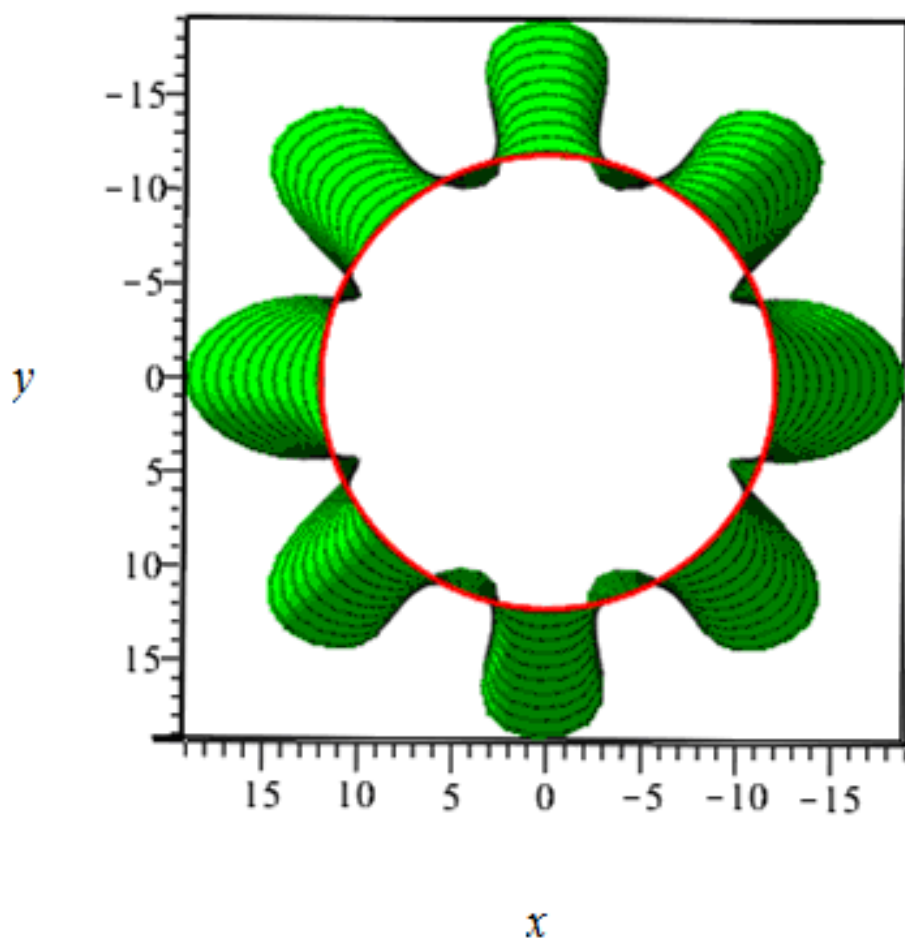

\begin{tabular}{|c|c|c|c|}
\hline Measures & Value, $\mathrm{cm}$ & Measures & Value, $\mathrm{cm}$ \\
\hline Height & 164 & \multirow{3}{*}{$\begin{array}{l}\text { Chest girth } \mathrm{O}_{\Gamma} \\
\text { Hip girth } \mathrm{O}_{\sigma} \\
\text { Skirt length } \mathrm{L}\end{array}$} & 96 \\
\hline Waist girth $\mathrm{O}_{\mathrm{T}}$ & 76 & & 104 \\
\hline $\begin{array}{l}\text { Projection distance from waist to hips } \\
\mathrm{h}\end{array}$ & 20 & & 53 \\
\hline Waist radius $R_{t}$ & 12.1 & $\begin{array}{l}\text { Angle between the cone } \\
\text { generatrix and base } \beta \text {, } \\
\text { rad. }\end{array}$ & 1.35 \\
\hline Hip radius $R_{b}$ & 16.55 & Generatrix length $L$ & 53 \\
\hline Radius of the skirt bottom $R_{n}$ & 23.62 & Length of the generatrix & 55.62 \\
\hline
\end{tabular}

Figure 2. Projection of the one-layer conic skirt of big conicity to the horizontal plane

Table 1. Anthropometric data of a standard female figure and values of the cone parameters 
of the cone top $R_{v}$

Central angle of the 1.37

evolvent $\alpha$, рад.

For visualizing the product prototype form, let's consider an example of the big conicity skirt for a standard female figure. The main sizes of the standard female figure and the relevant sizes of the conic skirt are represented in Table 1.

Let's consider the surface element of the one-layer thin shell, which is comprised between the parallel horizontal planes $z=h_{R}$ and $z=h_{R}+\Delta h$ in the right circular truncated cone (Figure 1), its length is equal to $2 \pi R$. It is also necessary to note that in the shell forming, the surface element acquires a space form rather than a horizontal form (Figure 3)

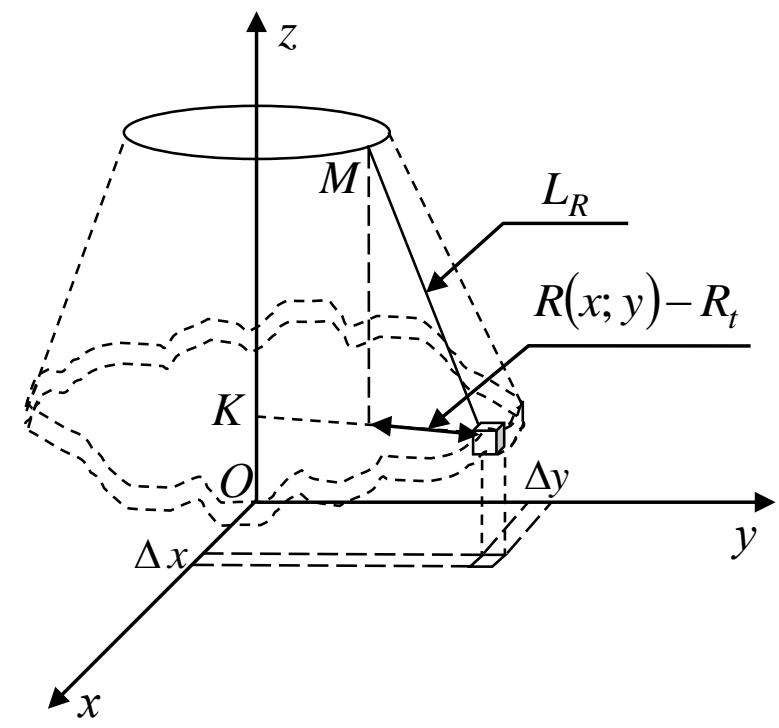

Figure 3. Space form of the shell surface element

The problem of setting a form of the shell surface element in polar coordinates and its space location show that it is necessary to introduce a new coordinate system for describing the surface element as a middle curve in the space - in the parametrical form

$$
x=x(t) ; y=y(t) ; z=z(t) .
$$

Now the polar radius is set in the form

$$
r(t)=\sqrt{x^{2}(t)+y^{2}(t)+z^{2}(t)}
$$

With account taken of transformations (6) and (7) the variational problem $(4,5)$ takes on the form 


$$
\begin{gathered}
\frac{g \cdot L}{\cos \beta} \int_{t_{1}}^{t_{2}} \rho(x, y, z) \cdot\left(L-\sqrt{L^{2}-\left(r(t)-R_{T}\right)^{2}}\right) d t+ \\
+\frac{L}{2 I \cos \beta} \int_{t_{1}}^{t_{2}} B(x, y, z)\left(R_{T}-r(t)\right)^{2} d t \rightarrow \min , \\
\int_{t_{1}}^{t_{2}} \sqrt{\left(\frac{d x}{d t}\right)^{2}+\left(\frac{d y}{d t}\right)^{2}+\left(\frac{d z}{d t}\right)^{2}} d t=2 \pi R .
\end{gathered}
$$

where $t_{1}$ corresponds to a value of the polar angle $\varphi=0$, while $t_{2}$ corresponds to a value of polar angle $\varphi=2 \pi$.

Let's suppose that the one-layer thin shell does not have seams and its parameters of the bending stiffness and the surface density are constant in any surface point. Then the formula (8) becomes simpler

$$
\frac{g \cdot L \cdot \rho}{\cos \beta} \int_{t_{1}}^{t_{2}}\left(L-\sqrt{L^{2}-\left(r(t)-R_{T}\right)^{2}}\right) d t+\frac{L \cdot E}{2 \cos \beta} \int_{t_{1}}^{t_{2}}\left(R_{T}-r(t)\right)^{2} d t \rightarrow \min
$$

where $E=\frac{B}{I}-$ is a material elasticity module.

For solving the variational problem $(10,9)$ let's draw up the Lagrange function

$$
\begin{aligned}
& F=\rho \cdot g \cdot\left(L-\sqrt{L^{2}-\left(r(t)-R_{b}\right)^{2}}\right)+\frac{E}{2} \cdot\left(R_{b}-r(t)\right)^{2}- \\
& -\lambda \sqrt{\left[x^{\prime}(t)\right]^{2}+\left[y^{\prime}(t)\right]^{2}+\left[z^{\prime}(t)\right]^{2}},
\end{aligned}
$$

where $\lambda-$ is the Lagrange multiplier.

For the function (11) it is necessary to find the unconditional extremum. The Lagrange function does not depend on the parameter $t$, or

$$
F=F\left(r, \frac{d x}{d t}, \frac{d y}{d t}, \frac{d z}{d t}\right)
$$

The minimum for (10) must be found according to the functions $x=x(t), y=y(t)$ and $z=z(t)$. In order to simplify the problem, let's neglect a change in the vertical values on the middle curve $z=z(t)$.

Then in order to solve the variational problem for finding the conditional extrimum of the functional (10) with the constraint equation (9) according to (Alfutov, 2010) we can obtain the Euler equation system for the function (11) 


$$
F_{x}^{\prime}-\frac{d}{d t} F_{x^{\prime}}^{\prime}=0, \quad F_{y}^{\prime}-\frac{d}{d t} F_{y}^{\prime}=0
$$

Since the Lagrange function (11) does not depend on the parameter $t$, then each of equations of the system (12) admits the first integral

$$
F-x^{\prime} \cdot F_{x^{\prime}}^{\prime}=C_{1}, F-y^{\prime} \cdot F_{y^{\prime}}^{\prime}=C_{2}
$$

where $C_{1}, C_{2}-$ are the arbitrary constants.

From (8) we can find the partial derivatives $F_{x^{\prime}}^{\prime}=\frac{\partial F}{\partial x^{\prime}}$ и $F_{y^{\prime}}^{\prime}=\frac{\partial F}{\partial y^{\prime}}$

$$
\frac{\partial F}{\partial x^{\prime}}=-\frac{\lambda \cdot \frac{d x}{d t}}{\sqrt{\left(\frac{d x}{d t}\right)^{2}+\left(\frac{d y}{d t}\right)^{2}}}, \frac{\partial F}{\partial y^{\prime}}=-\frac{\lambda \cdot \frac{d y}{d t}}{\sqrt{\left(\frac{d x}{d t}\right)^{2}+\left(\frac{d y}{d t}\right)^{2}}}
$$

When inserting the first function from (14) in the first equation of the system (13), after simplifications, we can obtain

$$
\begin{aligned}
& F=\rho \cdot g \cdot\left(L-\sqrt{L^{2}-\left(r(t)-R_{b}\right)^{2}}\right)+\frac{E}{2} \cdot\left(R_{b}-r(t)\right)^{2}- \\
& -\frac{\lambda\left[y^{\prime}(t)\right]^{2}}{\sqrt{\left[x^{\prime}(t)\right]^{2}+\left[y^{\prime}(t)\right]^{2}}}=C_{1},
\end{aligned}
$$

Similarly, let's insert the second function from (14) in the second equation of the system (13)

$$
\begin{aligned}
& F=\rho \cdot g \cdot\left(L-\sqrt{L^{2}-\left(r(t)-R_{b}\right)^{2}}\right)+\frac{E}{2} \cdot\left(R_{b}-r(t)\right)^{2}- \\
& -\frac{\lambda\left[x^{\prime}(t)\right]^{2}}{\sqrt{\left[x^{\prime}(t)\right]^{2}+\left[y^{\prime}(t)\right]^{2}}}=C_{2},
\end{aligned}
$$

Thus, the system of equations (15) and (16) can be simplified to the form 


$$
\left\{\begin{array}{l}
F=\rho \cdot g \cdot\left(L-\sqrt{L^{2}-\left(r(t)-R_{b}\right)^{2}}\right)+ \\
+\frac{E}{2} \cdot\left(R_{b}-r(t)\right)^{2}-\frac{\lambda\left[y^{\prime}(t)\right]^{2}}{\sqrt{\left[x^{\prime}(t)\right]^{2}+\left[y^{\prime}(t)\right]^{2}}}=C_{1} ; \\
\lambda\left(\left[x^{\prime}(t)\right]^{2}-\left[y^{\prime}(t)\right]^{2}\right)=\left(C_{1}-C_{2}\right) \sqrt{\left[x^{\prime}(t)\right]^{2}+\left[y^{\prime}(t)\right]^{2}} .
\end{array},\right.
$$

The approximate solution of the system (17) was obtained in the form

$$
\left\{\begin{array}{l}
x=\cos t \cdot(p+q \cos (m t))-s \cdot \sin t \cdot \sin (2 m t) \\
y=\sin t \cdot(p+q \cos (m t))+s \cdot \cos t \cdot \sin (2 m t)
\end{array}\right.
$$

\subsection{Approximate solution and visualization of the flexible shell in Maple}

The package Maple 2019 has the interactive graphics capabilities and makes it possible to visualize the products on the basis of the symbol mathematics (Kolin, 2009). The package is user-friendly, its language has a crisp logic that is understandable not only to a professional programmer. In Maple it is possible to create simple packages of the applied programs and to embed them in a comprehensive program. Maple chooses the necessary types of variables and checks the correctness of the operations performance automatically. Maple does not require a description of variables and a strict record formalization. In the Maple system, graphic objects can be represented both in the static form and in the form of a two-dimensional or three-dimensional animation. These system capabilities can be used to show the real-time processes.

Building the middle curve in the Maple 2019 environment (Mitsik, Byrdina \& Bekmurzaev, 2017) for a surface element of the elastic inextensible shell with the curve parameters, which correspond to Table 1, is represented in Figure 4.

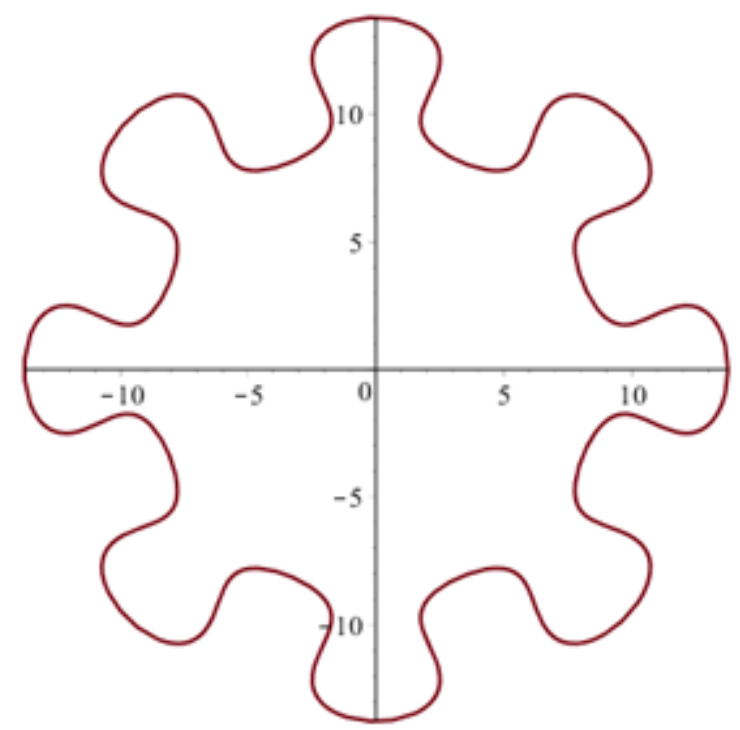

Figure 4. Building of the form of the shell surface element in the Maple 2019 environment

A form of the model middle surface is described in the cylindrical coordinate system in the form 


$$
\left\{\begin{array}{c}
x=\cos t \cdot\left(p_{1}+q_{1} \cos \left(m_{1} t\right)\right)-s_{1} \cdot \sin t \cdot \sin \left(2 m_{1} t\right) \\
y=\sin t \cdot\left(p_{1}+q_{1} \cos \left(m_{1} t\right)\right)+s_{1} \cdot \cos t \cdot \sin \left(2 m_{1} t\right) \\
0 \leq z \leq H .
\end{array}\right.
$$

where $p_{1}=a_{1}+b_{1} z ; q_{1}=a_{2}+b_{2} z ; \omega=8$.

A graphic image of the flexible elastic inextensible one-layer conic shell in the Maple 2019 environment is shown in Figure 5.

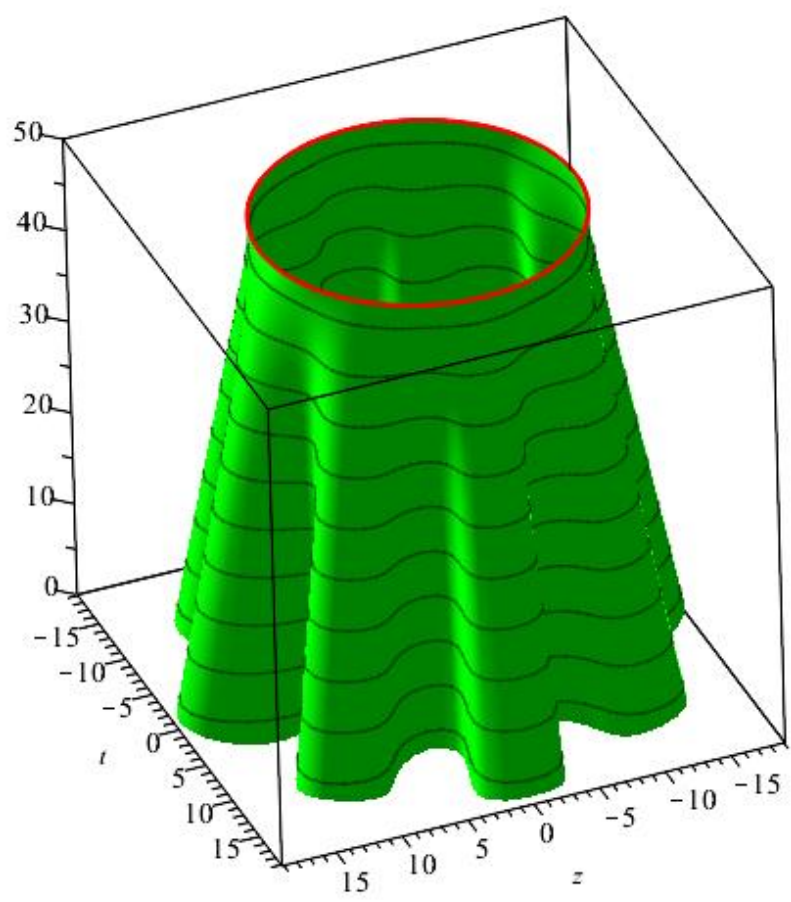

Figure 5. Visualization of the one-layer shell in the Maple 2015 environment

The main goal of the shell structures designing is to obtain the volume form of a faceted product and, on the contrary, the exact geometric mapping of the structure parts surface, or the envolvents obtaining. An anthropometric characteristic of the human figure serves initial information for designing the shell structures. Areas of the human body are complicated and diverse (they are close to surfaces like circular and elliptical one- and two-sheet hyperboloids, circular and elliptic paraboloids, ellipsoids and others), they widely use an approximation of composite surfaces with parts (sections) of simple surfaces (Tupikova, 2015).

The human body surface is broken into areas for convenience, which are approximately considered as parts of simple geometrical surfaces: cone, cylinder, sphere, while loops of the horizontal sections are approximated with circumferences and ellipses. According to V.Z. Vlasov, the founder of the shell theory, the clothes can be characterized by the volume geometrical shapes and considered as the shell surfaces (Tupikova, 2015).

The approximate evolvent of the mannequin surface, which is built according to the methods developed in Saint-Petersburg State University of Technology and Design, is represented in Figure 6. 


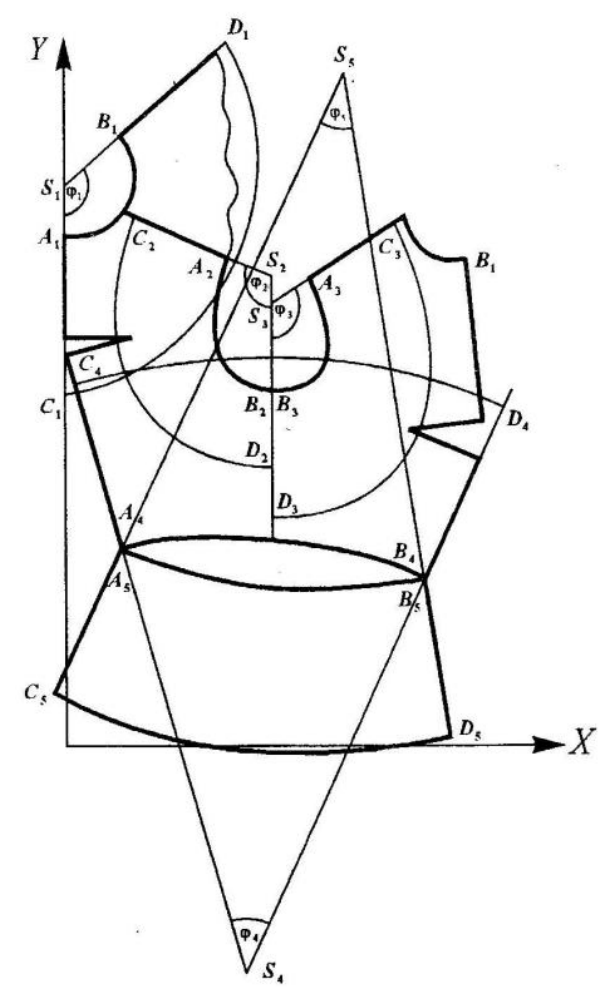

Figure 6. Approximate evolvent of the mannequin surface

The clothes designing researchers detected a possibility of the human body characteristic by the volume geometrical shapes, but the interrelation between the initial clothes form and the space form, which they take on the human figure, is not established. Thus, it is necessary to study this interrelation with account taken of the design solution of the product model and the material properties, which are used when the product is made.

The first research in the Russian Federation in the field of the computer clothes simulation was conducted by I.S. Zak, O.D. Marchenko and R.I. Sizova (2000), scientists of the Central Research Institute of Sewing Industry. A process of the three-dimensional clothes simulation included the development of basic clothes design and the subsequent superposition of design-decorative elements with a possibility of choosing them from the database.

A.I. Martynova, E.G. Andreeva, I.A. Petrosova and E.V. Lavris (2011), scientists of Moscow State University of Design and Technology, offered the methods of designing the fabric few-seam shells, whose peculiarity is that the whole process of calculating the product structure and form is performed in the in three-dimensional space without transition to the two-dimensional evolvents, which ensures the calculations accuracy and the labor saving.

N.N. Razdomakhin, E.Ya. Surzhenko and A.G. Basuev (Saint-Petersburg State University of Industrial Technologies and Design) in their papers developed an algorithm of the geometrical simulation of the dot and linear frameworks of the three-dimensional surfaces of a figure of a human being and clothes. And the model structure is based on algorithms of interrelation of the design dots of a three-dimensional form of clothes and anthropometric dots of the mannequin. A mathematical model of the clothes surface forming is obtained, in which the arc measurements of a human figure are used as control measurements after its volume surface is set (Razdomakhin et al., 2004).

Modern developments of simulating the composite surfaces from the woven materials are offered in the papers by V.D. Frolovsky, D.V.Frolovsky, V.V. Landovsky (2004, 2005), scientists of Novosibirsk State Technical University. The authors offer approaches of the computer simulation for the clothes surfaces of zero Guassian curvature as well as for the surfaces of positive or negative Guassian curvature. Calculation of building the evolvents and quasi-evolvents is represented on the 
basis of a method of energy functions, which consists in the total energy calculation (potential energy and deformation energy) in each dot of the surface.

K.Y.Sze and X.H. Liu (China) in their papers consider an approach to the woven products as to a thin bending elastic shell. A thin shell is regarded as an elastic plastic environment. In order to describe the product middle surface, the finite-difference schemes with account taken of elastic and plastic deformations are used. The represented methods of calculating the products geometry is illustrated by the model examples, which visually show a process of the materials forming with a set geometry of the product evolvent, the boundary conditions and the product input parameters (Sze \& Liu, 2007).

B. Thomaszewski, M. Wacker and W. Straber (2006), the German researchers, proposed simulating the fabric behavior by a finite elements method and with account taken of the stretching energy, fracture energy and flexural energy. A fabric is considered as a thin flexible shell, and the clothes surface geometry can be assessed locally.

When simulating the fabric behavior and animation of the three-dimensional clothes models the American researchers D. Baraff and A. Witkin used an algorithm of the modified conjugate gradients, which was improved by the Canadian scientists U. Ascher and E. Boxerman (2003) by implicit integrating methods increasing a material simulation step with the set restraints.

The Irish scientists D.E. Ilea and P.F. Whelan (2011) developed a way of an adaptive integration of color and a structure of the three-dimensional virtual object on the basis of its segmentation representing a process of the digital image division into a certain number of pixels.

The described analysis of domestic and foreign research shows the importance of development of the theoretical fundamentals of the virtual presentation of a volume-space form of shell structures. Creation of an adequate model of the shell space form with account taken of the materials properties requires the solution to a problem for finding the surface form by an analytical way, the building of a mathematical model of the structure space form and its subsequent computed $3 \mathrm{D}$ visualization.

In order to calculate a form of the product prototype, there is a need for a 3D-model of the studied structure. To this end, in the Maple environment, the programs of visualizing the thin elastic shell were developed. These programs have their peculiarities and errors of building the elements of surfaces and space curves. The emerging difficulties of describing a form of the surface elements are solved by computer geometry methods that make it possible to graphically visualize the structural peculiarities of the complex geometry surface, their joining and coupling

In order to analyze a space form of the shell structure in the stress and strain state, it is necessary to know the maximum fold flexures (Figure 2), the maximum normal stresses, and the magnitudes of flexures and stress intensity in each dot of the shell structure.

It should be noted that the famous authors in their papers did not consider the building of a volume and space form of the flexible elastic shells of big conicity (Figure 5). It was established that as the shell conicity grows, a number of its folds and the maximum fold flexures increase too. A number of folds increases if the bending shell stiffness decreases.

\section{CONCLUSION}

The developed theoretical methods and the software make it possible to visualize a space form of the flexible inextensible conic shells and to assess the artistic-aesthetic indicators of the product, while the horizontal projection makes it possible to determine a quantity and a depth of the folds occurence.

The application of program products in designing the manufactured articles makes it possible to reduce the material and labor expenses for creating the new clothes models through creating the virtual standards of 3D skirt models, a possibility of operative changes in the model standards and their 
transmission through the internet network. The program can serve as an auxiliary tool for the sewn products designers.

The commercial program complexes contain algorithms that are not known to the user, which creates difficulties for their efficient application. The disagreements of building the surface elements and the spatial curves can appear too.

Visualizations of a prototype of the shell structure in the stress and strain state, which are represented in Figures 2 and 5, and which are obtained by a developed program module, in the designer-friendly form, clearly reflect the space-volume shell form with a possibility to choose a field of the flexures and a quantity of folds.

The offered program module can be used during designing and calculating the thin-walled shell structures made of flexible and elastic material, which are fastened on the upper edge and located freely in the field of gravitational and elastic forces. The module can also be used to analyze the approximate solutions obtained by the commercial program products for engineering calculations.

\section{REFERENCES}

Alfutov, N. A. (2010). Stability of Elastic Structures. Berlin: Springer-Verlag.

Ascher, U., \& Boxerman, E. (2003). On the modified conjugate gradient method in cloth simulation. The Visual Computer, 19(7-8), 526-531.

Bekmurzaev, L. A., Byrdina, M. V., \& Nazarenko, E. V. (2014). Research and simulation of the thin shell forming. Scientific and Technical Volga Region Bulletin, 4, 58-64.

Buzov, B A. (2010). Materials science in manufacturing the light industry products. Garment manufacture. Moscow: Academia.

Byrdina, M. V., Mitsik, M. F., Bekmurzaev, L. A, \& Rubtsova, S. V. (2019). Surface visualization of flexible elastic shells. In 2019 IEEE East-West Design and Test Symposium EWDTS 2019. DOI:10.1109/EWDTS.2019.8884456

Frolovsky, V. D., \& Landovsky V. V. (2005). Explicit and Implicit integration in the problem of modeling of fabric based on particles method. In Proceeding of 9th Korean-Russian International Symposium on Science and Technology (June 26-July 2) (pp. 596-600). Novosibirsk State Technical University

Frolovsky, V. D., Landovsky, V. V. (2004). Modeling of fabric based on particles method. In Proceeding of the International Forum isiCAD (pp. 224-229). Novosibirsk: Ledas Ltd.

Ilea, D. E., Whelan, P. F. (2011). Image segmentation based on the integration of color - texture descriptors. A review. Pattern Recognition, 44(10-11), 2479-2501.

Kolin, G. (2009). Fashion and textile fabrics. Birth of new tendencies. Moscow: Grevtsov Publisher.

Kozlov, V. A. (2003). Theory and calculation of conic shells of a complicate geometrical structure (Doctoral dissertation). Voronezh.

Lan, P., \& Liu, M. (2011). Integration of Computer Aided Design and Analysis Using the Absolute Nodal Coordinate Formulation. In Fourth International Conference on Intelligent Computation Technology and Automation. DOI: 10.1109/ICICTA.2011.48 
Lavris, E. V. (2011). Theory and methods of designing the volume few-seam shells with triaxial and multiaxial structure. (master's thesis, Moscow State University of Design and Technologies). Moscow.

Mikkola, A. M., Matikainen, M. K. (2006). Development of elastic forces for the large deformation plate element based on the absolute nodal coordinate formulation. ASME J. Comput. Nonlinear Dyn, l(2), 103-108.

Mitsik, M. F, Byrdina, M. V., Bekmurzaev, L. A. (2017), Modelimg of developable surfaces of threedimentional geometric objects. In Proceedings of 2017 IEEE East-West Design and Test Symposium (8110086) EWDTS.

Official website of Maple (2018). URL: https://maplesoft.com/

Ohmori, H., Yamamoto, K. (1998). Shape optimization of shell and spatial structure for specified stress distribution. Memoirs of the School of Engineering. Nagoya Univ-50(1), 1-32.

Razdomakhin, N. N. (2004). Theoretical fundamentals and methodological support for threedimensional designing of the clothes. (Doctoral dissertation)

Schwab, A. L., Meijaard, J. P. (2009). Comparison of Three-Dimensional Flexible Beam Elements for Dynamic Analysis: Classical Finite Element Formulation and Absolute Nodal Coordinate Formulation. J. Comput. Nonlinear Dynam 5(1), 10. doi:10.1115/1.4000320.

Sze K.Y., Liu X.H. (2007). Fabric drape simulation by solid-shell finite element method. Hong Kong, PR China, pp.819-838.

Thomaszewski, B., Wacker, M., \& Straber, W. (2006). A consistent bending model for cloth simulation with corotational subdivision finite elements. Eurographics ACM SIGGRAPH Symposium on Computer Animation.

Tupikova, E. M. (2015). Calculation of thin elastic shells in the form of a long skew helicoid. Construction mechanics of engineering structures and constructions, 3, 24-28.

Zak I.S., Sizova, R. I., \& Marchenko, O. P.; (2000). A way of computer simulation of clothes. Russian Federation Patent for invention No. 2154391 RU.

\section{SEMBLANCE OF THE AUTHORS}

Marina V. Byrdina: PhD in Technology, Institute of Service Sector and Business (branch) of Don State Technical University in the city of Shakhty.

Mikhail F. Mitsik: PhD in Technology, Institute of Service Sector and Business (branch) of Don State Technical University in the city of Shakhty.

Lema A. Bekmurzaev: Full Doctor in Technology, Institute of Service Sector and Business (branch) of Don State Technical University in the city of Shakhty.

Svetlana V. Kurenova: PhD in Technology, Institute of Service Sector and Business (branch) of Don State Technical University in the city of Shakhty.

Anastasiya A. Movchun: student, Institute of Service Sector and Business (branch) of Don State Technical University in the city of Shakhty. 